\title{
Interregional differentiation of investment attractiveness in Russia: new evaluation tool
}

\author{
Irina Grishina ${ }^{1,2 *}$, and Vladimir Myakshin ${ }^{3}$ \\ ${ }^{1}$ Russian Foreign Trade Academy of the Ministry of Economic Development of the Russian \\ Federation, Council for the Study of Productive Resources, Vorobyevskoe Shosse 6A, Moscow, \\ 119285, Russian Federation \\ ${ }^{2}$ Russian Presidential Academy of National Economy and Public Administration, Institute of Applied \\ Economic Research, Prosp. Vernadskogo 82, Moscow, 119571, Russian Federation \\ ${ }^{3}$ Northern (Arctic) Federal University named after M.V. Lomonosov, Department of Financial Law \\ and Jurisprudence, Severnaya Dvina embankment, 17, Arkhangelsk, 163001, Russian Federation
}

\begin{abstract}
The insufficient validity of the positioning of regions in different Russian investment ratings, in particular, the observed convergence of regional assessments, is due to a number of methodological problems. The purpose of the study is to develop a tool to determine the impact of various components of investment attractiveness on the growth of investment activity in the regions and to ensure a balance of interests of the actors of the investment process (regional government bodies, private investors, the population). We developed an original system of indicators for comprehensive assessment of the investment attractiveness of regions including productional, financial, socio-economic, natural, innovative, infrastructure, and personnel components and proposed the balanced assessment method. Based on the matrix of integral indicators we show significant interregional differentiation of investment attractiveness for the North-Western Federal District and determine the key factors of investment attractiveness formation for those regions, including natural resources - for 5 regions, innovations, infrastructure and personnel for 3 , productionfinancial factors for 2 , and socio - economic factors for 1 region. The developed methodology allows to justify the priority directions of increasing investment attractiveness aimed at activating investment processes in Russia's regions.
\end{abstract}

Keywords: Russian region, investment activity, investment attractiveness assessment, balanced scorecard, North-Western Federal District.

\section{Introduction}

The Russian regions vary greatly in terms of their investment attractiveness, challenging the socio-economic development in the Russian Federation. Together with the growth in households' unused savings, discrepancy between the actual volume of investments in the real sector of economy and the sufficiently high level of investment resources, available to

* Corresponding author: grishinaiv@mail.ru 
both institutional and private investors, is indicative of poorly managed interaction and lacking understanding between the state and businesses on the investment side. The structural and dynamic analysis of the investment processes in the constituent entities of the Russian Federation shows further strengthening of structural imbalances caused by the major portion of investment being channeled into well developed, export-oriented raw materials industries. Among subjective, but significant, reasons why the economies of many Russian regions continue to be dependent on raw material exports, is the lack of sufficiently accurate and representative estimates for identifying alternative investment possibilities, which, in turn, adds to the relevance of new methodologies for evaluating regional investment attractiveness.

The domestic methodology for exploring the investment attractiveness of the Russian regions draws largely on the concepts and approaches developed by $\mathrm{H}$. Henzler, $\mathrm{Ph}$. Kotler, P. Walters, B. Toyne, research teams at University of Toronto and Harvard Business School, who operate in their economic descriptions of the countries and regions of the world such notions as 'investment attractiveness', 'investment climate' and 'investment risks'. At regional level, the investment attractiveness research is pursued by I. Roizman, I. Romanets, V. Sekrekov, A. Folomyev, among others. Highly informative among the recent publications are those by V. Yakimova, S. Khmur, E. Bunova, etc. [1-2]. At the same time, the currently dominant approaches to assessing the investment attractiveness of Russia's regions are implemented, as a rule, by rating agencies [3-5], and are aimed primarily at reflecting the efforts of regional authorities to create a favorable investment climate, but not at reflecting the actual investment activity in the regions. We do not find any approaches which also set themselves the tasks to be useful for fundamentally different interests of different user's categories.

This paper proposes a new methodological approach to evaluating the investment activity which is based on balanced scorecard (BSC) approach and is reflective of the many interaction possibilities for state and private businesses. The proposed scorecard can be used as a tool for factorial assessment of regions' investment attractiveness in relation to investment activity, while ensuring a balance of interests among investment stakeholders. Methodologically, the proposed scorecard relies on a systems approach to investment attractiveness evaluation, BSC approach, and the Russian and international experience in regional investment attractiveness studies. The development of the proposed BSC coincided with promotion in Russia of new institutional mechanisms to support the regional economic development. In our study, we explore the economic and social relations that emerge between regional authorities and private business as regional investment strategies continue to be developed. Specifically, the study aims to evaluate the investment attractiveness of the NorthWestern Federal District (NWFD), comprised by eleven regions with varying performance in socio-economic development and investment strategies. Since five of the eleven regions partially (Karelia, Komi, Arkhangelsk Region) or completely (Nenets Area, Murmansk) form part of the Arctic Zone of the Russian Federation, their investment processes are constrained by factors of natural, climatic, social, institutional, and infrastructure-related nature, increasing the cost of their investment projects. The economic structure of these regions is largely defined by their availability of natural resources, which represent the highest-scoring component of their investment performance. Their remoteness from the central part of Russia and extreme natural and climatic conditions explain undeveloped infrastructure, shortage of personnel, limited products and services market capacity, and ever increasing heating and electricity costs. Unlike them, St. Petersburg as a city of federal significance occupies a special place in NWFD (its 2020 contribution to NWFD's GRP amounts to 47\%), enjoying a high-ranking investment-wise due to ample human capital, large market capacity, highlevel innovation activity, developed infrastructure, etc.

The hypothesis we formulated for our study has been verified: The lack of balance in the regional investment policies represents is a factor limiting the regional investment potential 
(as was convincingly shown by case study of the Northwestern Federal District). With a balanced scorecard-based approach, it is possible to identify promising investment areas that can stimulate investment and lead to better balanced economic development in each region.

\section{Methodology and Methods}

The high discrepancy between the Russian regions in terms of economic sectors performance, socio-economic development and investment activity determines the need for further research into regional investment attractiveness and opportunities. In this study, we have modified a product of our many-year efforts, initiated by the Council for the Study of Productive Forces (currently - Russian Foreign Trade Academy under the management of the RF Ministry of Economic Development), to produce a comprehensive methodology for evaluating the investment climate of the Russian regions, to accurately reflect the current economic trends and statistical accounting. [6]. The modification consists in incorporating into the methodology the developments of the BSC approach proposed by R. Kaplan and D. Norton. [7].

As a performance evaluation system, the Balanced Scorecard has evolved from a simple matrix-based performance evaluation approach to a strategy management tool. A major contribution to further development of the BSC model was made by M. Brown, P. Niven, and N. Olve while studying economic systems at different levels. [8-10]. BSC model is commonly as a tool for corporate performance evaluation [11-13], whereas there has been little experience using its methodology in assess the investment attractiveness of national and regional economic systems. Therefore, the BSC-based regional investment studies have potential as capable of furnishing the state economic decision-making with new results and data. In our model of BSC, the evaluation is reflective of the socio-economic conditions of Russian regions and investment stakeholders' information needs. The Russian regions have been analyzed and rated in terms of their performance in key BSC perspectives (natural resource, socio-economic, production and financial, innovation and infrastructure, and personnel aspects). In developing our BSC model, we were governed by the following main principles: maximum representativeness and investment significance; consistency with investment stakeholders' interests; consistency of indicators with key investment-significant factors; investment-significant factors quantification; official statistics-based indicator; selection of target values based on regional investment processes studies in Northwestern Federal District (benchmarking against the performance in economically developed countries and the targets set by Russian national and federal projects). The sub-indices were selected for the BSC based on key trends and factors of investment climate in Northwestern Federal District, considering natural, social and institutional constraints, and the sectoral structure of the regional economy, which, in turn, makes it possible to identify ways to influence investment activity. The evaluation process uses a comparison between the calculated and the target scores for the sub-indices, the latter identified while monitoring the investment processes in NWFD regions. To calculate the overall investment attractiveness score, the subindices are converted into relative values using the multivariate L1-mean formula, with prior standardizing by way of normalizing the numerical values of each sub-index to a particular target value to avoid the influence from average investment attractiveness score across Russia.

To assess the investment attractiveness of the regions of the NWFD, the integrated indicators for each of the components of the BSC are calculated, as well as the final integral indicator using the multidimensional average formula: 


$$
X_{j}=\frac{\sum_{i=1}^{n} x_{i} \cdot k_{i}}{\sum_{i=1}^{n} k_{i}}
$$

where $X_{j}$ is integral level of investment attractiveness for the $\mathrm{j}$-th component; $x_{i}$ is an indicator determining the ratio of the numerical value of each particular indicator of the factorial attribute of investment attractiveness to the target value of the same indicator; $k_{i}$ is weighting factor of significance of the $\mathrm{i}$-th indicator; $i=1,2, \ldots, n$ is the number of private indicators of factorial signs of investment attractiveness within each component of the BSC; $j=1,2, \ldots, t$ is number of BSC components.

In this study, we did not use any weighing factors when calculating the overall scores as all selected indicators are interrelated with key parameters of investment attractiveness. This helped us ensure equal significance of indicators and achieve higher assessment objectivity (independence from expert assessments). The proposed method implies that the target scores of the key indicators comprising the BSC are reflective of the goals of regional investment policies. Serving as indicators of the extent to which these investment goals have been achieved are the actual scores. Promising investment areas are identified based on the revealed deviations in the actual indicator scores from the target ones (more than 25\%), while the balance degree of a regional investment policy is judged based on the degree of differentiation of the total indicators scores. [14]. The sub-indicators within the four perspectives (A-D) of the proposed BSC are presented for NWFD (in Table 2).

\section{Results and Discussion}

For model testing purposes, we used the investment performance of NWFD regions for the period between 2011 and 2018. The study made use of the empirical data obtained from the Russian Federal State Statistics Service, previous studies into the sector-specific performance of the regions, as well as current investment-related legislations and regulatory frameworks. Over the period between 2011 and 2018, positive dynamics in investment attractiveness have been found in all NWFD regions (with exception of Nenets Autonomous Area (NAA)). (Table 1). The investment attractiveness varies greatly among NWFD socio-economic conditions, infrastructure and market institutions development level, innovation activity, natural and climatic conditions, geographical location, interregional relations, foreign economic activity, availability of resources (natural, human, financial) for investment progress, and availability of energy and communications, with NAA scoring lowest -1.8 times lower than St. Petersburg, where almost $60 \%$ of the indices reach or are close to their target values.

Table 1. Dynamics of the total investment attractiveness score for NWFD regions (2011-2018).

\begin{tabular}{|l|c|c|c|c|c|c|c|c|}
\hline \multicolumn{1}{|c|}{ Russian Region } & $\mathbf{2 0 1 1}$ & $\mathbf{2 0 1 2}$ & $\mathbf{2 0 1 3}$ & $\mathbf{2 0 1 4}$ & $\mathbf{2 0 1 5}$ & $\mathbf{2 0 1 6}$ & $\mathbf{2 0 1 7}$ & $\mathbf{2 0 1 8}$ \\
\hline Saint-Petersburg & .68 & .75 & .81 & .76 & .72 & .84 & .85 & .87 \\
\hline Leningrad Region & .70 & .75 & .73 & .64 & .69 & .68 & .70 & .75 \\
\hline Vologda Region & .57 & .61 & .54 & .52 & .62 & .80 & .76 & .73 \\
\hline Kaliningrad Region & .57 & .57 & .54 & .55 & .61 & .62 & .68 & .71 \\
\hline Murmansk Region & .64 & .61 & .59 & .66 & .72 & .65 & .66 & .71 \\
\hline Komi Republic & .63 & .62 & .59 & .56 & .60 & .63 & .60 & .65 \\
\hline Novgorod Region & .61 & .60 & .54 & .57 & .60 & .58 & .56 & .65 \\
\hline Arkhangelsk Region & .33 & .39 & .44 & .50 & .54 & .55 & .57 & .64 \\
\hline Republic of Karelia & .53 & .51 & .51 & .51 & .56 & .56 & .59 & .63 \\
\hline Pskov Region & .47 & .51 & .49 & .47 & .54 & .44 & .56 & .52 \\
\hline Nenets Autonomous Area & .70 & .66 & .47 & .41 & .51 & .55 & .51 & .49 \\
\hline
\end{tabular}


Based on the results of the evaluation of each perspective in our BSC model, let us analyze the impact of investment-significant factors on the regions' investment attractiveness (Table 2). Our analysis of the performance demonstrated in Manufacturing and Finance (A.1-A.3) by Vologda and Novgorod Regions indicates these regions' having been productive investment-wise in 'manufacturing industries profitability', 'labor resources', 'environmental safety', and 'regional budget balance', which approximate their target values. There has been an increase in businesses with higher profit. The lowest scoring in Manufacturing and Finance are NAA (0.08) and Pskov region (0.41). This is due to low efficiency of their production and financial activities. High wear of fixed assets is observed in all NWFD regions, negatively affecting the production potential. In many regions, except St. Petersburg, Pskov and Kaliningrad Regions, 'environmental safety' indicator is close to its target value. In the regions comprising the RF Arctic zone, the total score tends to fluctuate due to varying efficiency of their manufacturing industries, hindering the growth of investment attractiveness. Deviating from their target values are 'number of profitable enterprises', 'mining profitability' (with exception of Murmansk region), 'profitability of labor resources' (except for Murmansk region and Komi Republic).

In three regions, St. Petersburg, Leningrad and Kaliningrad Regions, the increase in investment attractiveness is driven by Innovation, Infrastructure and Personnel, as shown by the positive dynamics in this perspective's indicators (B.1-B.3). In these regions, above their target values are "product investment intensity requirement' and 'infrastructure potential' (for St. Petersburg, this indicator significantly exceeds the target value); 'renewal of fixed assets' is close to its target value. These regions also show higher innovation-related expenditure. The region with lowest score in 'innovation potential' and Innovation at large is Pskov region (0.46). Vologda and Novgorod regions scow low in 'infrastructure potential'. Overall, low progress in Innovation, Infrastructure and Personnel as a key driver of investment activity has been shown by five regions that comprise the Arctic Zone, with low 'transport infrastructure' and innovation potential', 'renewal of fixed assets and 'personnel training' deviating from the target values further found inconsistency of these regions' personnel policy with economic targets. A factor positively influencing the investment attractiveness of these regions is 'sales investment requirement', which approximates its target value.

The analysis of region's performance in Natural Resources (C.1-C.3) enables a conclusion that in the five regions (Arkhangelsk, Murmansk, NAA, Komi, and Karelia) the investment attractiveness is contingent on resource supply. As follows from the Table 2 for Natural Resources, close to their target levels are 'economically active population' (0.7-0.9 range) and 'availability of own funding'. With exception of St. Petersburg, all the NWFD regions show negative dynamics in 'economically active population', which is indicative of their insufficient efforts to man the economies with sufficient personnel. In Karelia, Arkhangelsk, Novgorod, and Pskov Regions, 'electric energy per capita" shows consistent deviation from the target value. 'Favorableness of geographical location' is near its target value in Vologda, Novgorod, Leningrad, Kaliningrad, Pskov Regions, and St. Petersburg, promising better inter-regional and foreign trade prospects. 'Communications availability' approximates its target values in all regions apart from NAA.

Socio-economic factors appear to play a key role in shaping the investment attractiveness of Pskov region: approximating their target values are 'GRP dynamics', 'entrepreneurship development', 'property relations' and 'employee satisfaction'. The Social and Economic Perspective (D.1-D.3) shows low score in 'social security', 'openness of the economy, 'GRP per capita' and 'social sector financing'. 
Table 2. BSC indicators for measuring the investment attractiveness of the NWFD (2018).

\begin{tabular}{|c|c|c|c|c|c|c|c|c|c|c|c|}
\hline ens & 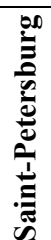 & 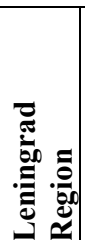 & 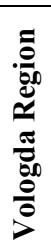 & 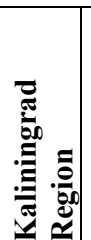 & 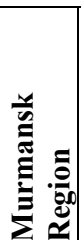 & 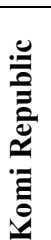 & 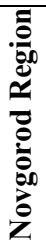 & 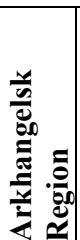 & 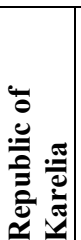 & 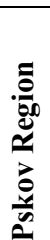 & 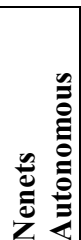 \\
\hline
\end{tabular}

A. Manufacturing and Finance

A.1. Financial performance indicators (High-performing businesses; Region's budget balance (revenues vs. expenditures); Overdue accounts payable)

\begin{tabular}{|l|l|l|l|l|l|l|l|l|l|l|l|} 
Indicator score & .70 & .85 & .74 & .78 & .55 & .59 & .61 & .77 & .57 & .61 & .55 \\
\hline
\end{tabular}

A.2. Environmental safety indicators (Harmful emissions from all fixed sources, decontaminated) \begin{tabular}{|l|l|l|l|l|l|l|l|l|l|l|l} 
Indicator score & .56 & 1.04 & 1.07 & .38 & .89 & .40 & 1.20 & .95 & .49 & .42 & .00 \\
\hline
\end{tabular} A.3. Financial and operational performance indicators (Wear of fixed assets; Return on assets within Mineral Production sector, Manufacturing sector, Energy, Gas and Water Management sector; Profitability of sales within Mineral Production sector, Manufacturing sector, Energy, Gas and Water Management sector; ROI of employees)

\begin{tabular}{|l|c|c|c|c|c|c|c|c|c|c|c|}
\hline Indicator score & .65 & .80 & 1.13 & .70 & .78 & .96 & .82 & .65 & .79 & .33 & -.21 \\
\hline $\begin{array}{l}\text { A. Perspective } \\
\text { score }\end{array}$ & .66 & .83 & 1.03 & .69 & .79 & .82 & .80 & .86 & .77 & .41 & .08 \\
\hline
\end{tabular}

B. Performance in Innovation and Personnel

B.1. Intellectual potential indicators (University-trained employees; Skill formation) \begin{tabular}{|l|l|l|l|l|l|l|l|l|l|l|l|} 
Indicator score & .45 & .44 & .46 & .45 & .46 & .47 & .46 & .40 & .46 & .46 & .47 \\
\hline
\end{tabular} B.2. Innovational potential indicators (R\&D expenditure; Technological innovation expenditure; Use of IT, share; Renewal of fixed assets; Sales investment requirement)

\begin{tabular}{|c|c|c|c|c|c|c|c|c|c|c|c|}
\hline Indicator score & .59 & .83 & .50 & .77 & .57 & .43 & .54 & .46 & .40 & .41 & .51 \\
\hline \multicolumn{12}{|c|}{ B.3. Infrastructural capacity indicators (Density of communication routes) } \\
\hline Indicator score & 7.96 & .74 & .24 & 1.38 & .47 & .08 & .59 & .08 & .18 & .71 & .00 \\
\hline $\begin{array}{l}\text { B. Perspective } \\
\text { score }\end{array}$ & 1.48 & .72 & .46 & .76 & .53 & .39 & .52 & .40 & .39 & .46 & .44 \\
\hline
\end{tabular}

C.1. Resource endowment indicators (Economically active population; Energy production; Mobile broadband subscriptions; Stationary broadband subscriptions; Internal corporate funds)

\begin{tabular}{|l|l|l|l|l|l|l|l|l|l|l|l|}
\hline Indicator score & .99 & .89 & .84 & .83 & 1.15 & 1.05 & .71 & .80 & .95 & .67 & 1.54 \\
\hline
\end{tabular}

C.2. Region's geographical location indicator (Favorableness of geographical location)

\begin{tabular}{|l|l|l|l|l|l|l|l|l|l|l|l|}
\hline Indicator score & 1.00 & 1.00 & 1.00 & 1.00 & 1.00 & .71 & 1.00 & 1.00 & 1.00 & 1.00 & .71 \\
\hline
\end{tabular} C.3. Natural climate favorableness indicators (Region's climatic conditions)

\begin{tabular}{|l|c|c|c|c|c|c|c|c|c|c|c|} 
Indicator score & .71 & .71 & .71 & .71 & .57 & .71 & .71 & .71 & .71 & .71 & .43 \\
\hline $\begin{array}{l}\text { C. Perspective } \\
\text { score }\end{array}$ & .95 & .88 & .84 & .84 & 1.05 & .95 & .75 & .82 & .93 & .72 & 1.22 \\
\hline
\end{tabular}

D. Social and Economic Perspective

D.1. Prospects of economic growth (GRP per capita; Dynamics of GRP; Inflation in consumer and manufacturing sectors; Property relations; Entrepreneurship development; Openness of economy) \begin{tabular}{|l|l|l|l|l|l|l|l|l|l|l|l|}
\hline Indicator score & .73 & .67 & .67 & .70 & .64 & .60 & .60 & .60 & .62 & .61 & .80 \\
\hline
\end{tabular} D.2. Social security indicators (Common diseases incidence; Injuries, intoxications and some other externally induced effects; Recorded crime)

\begin{tabular}{|l|l|l|l|l|l|l|l|l|l|l|l|}
\hline Indicator score & .41 & .65 & .39 & .53 & .46 & .29 & .34 & .32 & .35 & .42 & .32 \\
\hline
\end{tabular}

D.3. Employee satisfaction indicators (Welfare spending; Population with income above subsistence line; Unemployment rate; GRP/average wage growth ratio)

\begin{tabular}{|l|c|c|c|c|c|c|c|c|c|c|c|}
\hline Indicator score & .79 & .58 & .53 & .55 & .53 & .49 & .55 & .52 & .48 & .51 & .54 \\
\hline $\begin{array}{l}\text { D. Perspective } \\
\text { score }\end{array}$ & .68 & .64 & .57 & .62 & .57 & .50 & .53 & .52 & .52 & .54 & .62 \\
\hline Total score & .87 & .75 & .73 & .71 & .71 & .65 & .65 & .64 & .63 & .52 & .49 \\
\hline
\end{tabular}


For the regions comprising the Arctic zone, the analysis of Social and Economic Perspective has shown insufficient development of market economy institutions. These regions' low score in 'social security' relates to high 'morbidity rate'. In case of Leningrad Region, Kaliningrad, Novgorod, and Vologda Regions, the Social and Economic Perspective scores the middle range compared to other perspectives of our BSC model. In these regions, indicators such as 'GRP dynamics' and 'market economy institutions development' are close to their target values. At the same time, 'employee satisfaction' and 'social security' are two times lower than their targets (with exception of Leningrad Region). Leningrad Region scores high in this perspective mainly due to its high level of institutional development (market institutions) and as well as employment, which approximate their target values.

The main validation criterion of the developed method is represented by the results of correlation analysis of the relationship between performance scores across the NWFD regions, calculated using the proposed BSC model and the regions' total investment in fixed assets (time lag is 4 years) (Table 3). Ro Spearman's correlation coefficient varies between 0.673 and 0.886 , which indicates average and high level of correlation. Two-tailed significance does not exceed 0.05 for all correlation coefficients, evidencing sufficient reliability of the calculated correlation coefficients. The correlation analysis has revealed a fairly close relationship between the investment attractiveness indicators and the investment activity, which allows us to conclude that the results obtained by the proposed evaluation model correspond to actual investments.

Table 3. Correlation between investment attractiveness indicators and fixed capital investment of NWFD regions.

\begin{tabular}{|l|c|c|c|c|c|}
\hline \multirow{2}{*}{ Index } & \multicolumn{5}{|c|}{$\begin{array}{c}\text { Investment attractiveness (year N) } \\
\text { investment (year + 4) }\end{array}$} \\
\cline { 2 - 6 } & $\mathbf{2 0 1 0 \backslash 2 0 1 4}$ & $\mathbf{2 0 1 1} \backslash \mathbf{2 0 1 5}$ & $\mathbf{2 0 1 2} \mathbf{2 0 1 6}$ & $\mathbf{2 0 1 3} \backslash \mathbf{2 0 1 7}$ & $\mathbf{2 0 1 4 \backslash 2 0 1 8}$ \\
\hline $\begin{array}{l}\text { Spearman's correlation } \\
\text { coefficient }\end{array}$ & $.673^{*}$ & $.886^{*}$ & $.764^{*}$ & $.754^{*}$ & $.718^{*}$ \\
\hline Two-tailed significance & .023 & .000 & .006 & .007 & .013 \\
\hline
\end{tabular}

* Correlation significant at 0.5 (two-tailed).

\section{Conclusion}

The analytical advantages of the balanced scorecard model make it an effective tool for identifying regions' key priority areas for increasing the investment attractiveness. The study of the investment dynamics in the regions comprising the Northwestern Federal District has provided ample data for applying the BSC model to identify the patterns of investment performance and activity in these regions, based on a system of relevant indicators and subindices. The obtained results have allowed us to determine the degree of influence the various factors (Manufacturing and Finance, Natural Resources, Social and Economic Perspective, Innovation, Infrastructure and Personnel) have on the level of investment attractiveness. The identified divergence of the indicator scores across the BSC perspectives is indicative of the regional investment policies being poorly balanced, a factor limiting the implementation of the NWFD regions' investment potential.

The study is novel in that is has produced a balanced scorecard design allowing to measure the investment attractiveness of the Russian regions. Based on the use of federal data and statistics, the proposed toolkit ensures an objective, balanced assessment which relies on cause-effect relationships between key factors of investment attractiveness and key BSC indicators, while meeting the information demand of the stakeholders (regional authorities, private investors, population) in an investment process. The proposed BSC can be used for evaluating the investment attractiveness of not only NWFD regions, but also other 
regions of the Russian Federation in conditions of current economic instability induced by economic sanctions and pandemic-related social risks.

The evaluation criteria used in our BSC-based model for the Northwestern Federal District offer a helpful tool for identifying the priority development areas for better investment attractiveness and are intended for use by regional authorities in their investmentrelated decision-making for improved investment activity. In our approach to evaluating the NWFD regions' investment attractiveness, the emphasis is shifted from financial performance to intangible assets. Now that the BSC covers Innovation, Infrastructure and Human Resources, its application can improve decision-making as to regional economy's immunity to innovation and turn decision-makers' eye to human capital as a great advantage. For the NWFD regions to be able to enhance their investment attractiveness, an environment should be created for attracting private capital in key investment areas identified with the use of BSC. The deliverables of the study can be seen as a diagnostics tool for identifying the key challenges and shaping strategies towards increased investment attractiveness in the regions of the Northwestern Federal District. In addition to its reproducibility (applicability to any region), the proposed tool is open to change and can be altered subsequently as the NWFD regions progress in their economic and social development. Further research is designed to improve the BSC model structurally, considering the promising branches of the RF regions' economic specialization.

Acknowledgements: The research has been conducted in the framework of the R\&D state assignment of the Russian Presidential Academy of National Economy and Public Administration.

\section{References}

1. V. A. Jakimova, S. V. Hmura. Regional economy: theory and practice, 4, 780 (2020)

2. E. V. Bunova, O. S. Buslaeva, V. S. Serova, Regional economy: theory and practice, 4, $723(2020)$

3. 'National Rating Agency' VIII annual assessment of the investment attractiveness of Russian regions. Analytical report, February, 2021, 14 p. URL: https://www.ra-national.ru/sites/default/files/analitic_article/NRA_IPR_2020_fin.pdf

4. Rating of investment attractiveness of the RAEX regions for 2020. URL: https://raexa.ru/ratings/regions/2020

5. National investment rating of the 'Agency for Strategic Initiatives'. URL: https://asi.ru/government_officials/rating/

6. I. V. Grishina. Regional Economy. South of Russia, 1, 49 (2020)

7. R. S. Kaplan, G. Serafeim, E. Tugendhat, Harvard Business Review, 1, 127 (2018)

8. M. G. Brown, Beyond the balanced scorecard: Improving business intelligence with analytics. (2007)

9. P. R. Niven, B. Lamorte, Objectives and Key Results: Driving Focus, Alignment, and Engagement with OKRs. (2016)

10. N. G. Olve, J. Roy, M. Wetter, Performance drivers: A practical guide to using a balanced scorecard (2001).

11. T. N. Pes'yakova, R. V. Myakshina, Economics of Education, 3 (94), 51 (2016)

12. T. Hahn, F. Figge, Journal of Business Ethics, 4, 919 (2018)

13. M. M. Cheng, K. A. Humphreys, Managerial Auditing Journal, 4/5, 512 (2016)

14. V. N. Myakshin, A. E. SHaparov, D. V. Tihanova. 2021, Economy of region, 17(1), 235. (2021) 